IRA-International Journal of Education \& Multidisciplinary Studies ISSN 2455-2526; Vol.06, Issue 01 (2017)

Pg. no. 56-79

Institute of Research Advances http://research-advances.org/index.php/IJEMS

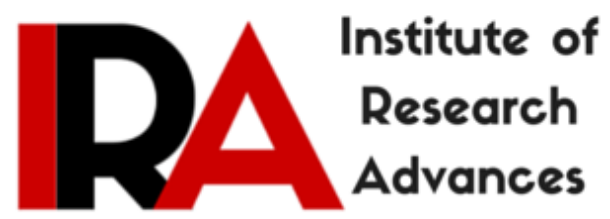

\title{
Vocabulary Strategy Training- A Rational Study among Engineering Students
}

\section{Dr. Afsha Jamal}

Assistant Professor, English

Prince Sattam Bin Abdul Aziz University

Wadi Al Dwaser, Saudi Arabia.

Type of Review: Peer Reviewed.

DOI: http://dx.doi.org/10.21013/jems.v6.n1.p4

\section{How to cite this paper:}

Jamal, A. (2017). Vocabulary Strategy Training- A Rational Study among Engineering Students. IRA International Journal of Education and Multidisciplinary Studies (ISSN 2455-2526), 6(1), 56-79. doi:http://dx.doi.org/10.21013/jems.v6.n1.p4

(C) Institute of Research Advances

\section{(c) EY-NC}

This work is licensed under a Creative Commons Attribution-Non Commercial 4.0 International License subject to proper citation to the publication source of the work.

Disclaimer: The scholarly papers as reviewed and published by the Institute of Research Advances (IRA) are the views and opinions of their respective authors and are not the views or opinions of the IRA. The IRA disclaims of any harm or loss caused due to the published content to any party. 


\begin{abstract}
The present study aims at identifying a specific set of strategies necessary for the enhancement of the vocabulary based on the needs survey. It also researches the effectiveness of strategy training course in improving students' competence in English.
\end{abstract}

\title{
Proficiency Level of the Students
}

The study has observed that there are a few who know English almost as their teachers do, because they come from an urban-English medium background. And there are majorities, who are unable to use English for writing and speaking, while a few have only a modicum of English.

The curriculum designed by the two universities under the present study benefits the bright students while the weak ones find it difficult. The students in the Engineering colleges exhibit an achievement level that is between the beginner and the intermediate level. Their exposure to the language is 12years $(10+$ 2).That is ten years of schooling and two years of Intermediate course. The findings of the survey reveal that the proficiency level of the students is below the expected level due the diverse backgrounds.

\section{The Learner:}

The learners in the Engineering colleges are more likely adolescents. They are difficult to handle. Some of them can be the fastest learners while others class slow. The incentives, the motives and the learning strategies vary from student to student due to their varied background. As they come from rural or urban areas having studied in English or Regional media. These factors have a psychological impact on them. The students are capable of expressing their purpose/nee in learning the language.

However, it is observed that most of the students do not really understand why they need English and what type of English they need. Hence it is necessary to motivate these adolescents to realize the utility of English not only to achieve the objective of enabling students to do well in their academic setting but also to perform effectively later in their job situations.

\section{The Teacher}

With the shift in emphasis from teaching to learning, the focus is on the learner and his/her learning strategies. With this shift in paradigm the teachers' role has also undergone a change. An Engineering teacher is expected to be a manager, facilitator and a co-participant. They are all post graduates in English literature. It is not mandatory for the teachers to undergo any training in the teaching techniques. As far as the teaching techniques are concerned they are familiar with only the lecture method.

\section{Rationale for Strategy Training}

The preliminary survey carried out by the researcher form the basis for designing a strategy training course. The survey reveals that the engineering students of three districts in A.P-Kishna, Guntur and Prakasam use Guessing, Memory, and Autonomy strategies.

The purpose of the Strategy Training Course is to:

- Create awareness of the learning strategies that engineering students have been using.

- Motivate them use appropriate strategies that would improve their vocabulary knowledge. 
- Stimulate them to be more self-reliant through autonomous language learning.

- Develop confidence among them in the application of Vocabulary strategies.

- Ultimately, help them improve their proficiency in English.

\section{Sample for Pre-Test \& Post Test}

The current study has selected two groups to examine the efficacy of the 'Strategy Training Course'. It may be hypothetical to provide training to a larger group. Hence, total 60 engineering students are chosen from Laki Reddy Bali Reddy College of Engineering situated in the Krishna District of A.P. They belonged to the two sections of Mechanical Engineering branch. The sample is divided into two groups namely the experimental and control groups. Thus, out of 60 students, 30 are treated as control group while 30 an experimental group. To find out the compatibility of the two groups in terms of their competence in English, a pre- test is administered. The experimental group is exposed to strategy training.

\section{Rationale for Strategy Training Course}

Initially, a Pre-Test is administered among the two groups and the scores are recorded and compared. This has exposed the vocabulary comprehension among the engineering students of A.P. Later, the experimental group is given training in the application of strategies. The control group is taught the same material without any training.

Thus, a Pre-Test is administered second time among the groups and the results are analyzed in the following method:

- The comparative performance of the two groups, one with the other for the first and second English Proficiency tests.

- The relative performance of the same group in the first and second English Proficiency tests.

The researcher has conducted the training session to the experimental group and comparative performance of both the groups is the benchmark to measure the effectiveness of the strategy training.

\section{Tool Used for Pre-Test \& Post-Test}

The Pre-Test presented in the Annexure: 5 is as mentioned earlier to study the proficiency and competence of the sample. The test is taken by the two sections of same Mechanical Branch-A\&B.

On Contrary to the usual question papers based on textual material that the students attempt in their colleges, the test is designed to test their efficiency in vocabulary based on the formats of GRE, GMAT,TOEFL and MNC Placements Test papers. It is designed to test the English Proficiency of the sample before the strategies training. It is conducted without prior notice or announcement of the test time and date. Hence, the researcher received surprising response from the sample. It is done deliberately to expose their actual vocabulary condition. The following procedure is taken up during the administration of the Pre-Test.

- No prior intimation to the sample is made of the date and time of the test.

- $\quad$ No guidance is provided.

- $\quad$ They are requested to answer truthfully and sincerely. 
- To lessen their apprehension, they are assured that the marks scored in the test would not affect their academic achievement in any way. They are further ascertained that their marks would be kept confidential.

- Surprisingly, the sample showed keen interest in knowing their marks in terms of their competence level in English.

- $\quad$ The results of both Pre-Test and Post-Test are assessed and analyzed.

\section{Pattern of Pre-Test}

Verbal ability is the major part of the requirements sought by all the entrance examinations. They measure English language proficiency in reading, listening and writing. Hence, the Pre-Test is prepared by the researcher to test the verbal ability of the engineering students.

The placement and other entrance tests comprises these aspects of language skills consisting of Sentence correction, Sentence Improvement, Sentence Formation, Completing Statements, Ordering of Words \& Sentences, Analogies, Reading Comprehension, Antonyms, Synonyms, Idioms \& Phrases, One word Substitute, Change of Voice and Speech, Listening Comprehension, Error identification, Critical reasoning, Analysis of Argument and issue, Paragraph Formation.

\section{Mid-Research Activity}

Hence, the Pre-Test is based on only vocabulary components of English language-- Synonyms, Idioms \& Phrases, One word Substitute, Change of Voice and Speech. ( Refer to Annexure: 1)Marks for different sections along with the time allotted for each section are given below:

\begin{tabular}{|l|l|l|}
\hline Topic & Marks & Duration \\
\hline Synonyms & $5 \mathrm{M}$ & $5 \mathrm{mts}$ \\
\hline Idioms \& Phrases & $5 \mathrm{M}$ & $5 \mathrm{mts}$ \\
\hline One word Substitute & $5 \mathrm{M}$ & $5 \mathrm{mts}$ \\
\hline Change of Voice & $5 \mathrm{M}$ & $10 \mathrm{mts}$ \\
\hline Speech & $5 \mathrm{M}$ & $10 \mathrm{mts}$ \\
\hline Total & $30 \mathrm{M}$ & $45 \mathrm{mts}$ \\
\hline
\end{tabular}

Table: 1

\section{Pre-Test:}

The Pre-test has covered most of the vocabulary elements of English language.

\section{Trial:}

Thus, a trial is attempted by the researcher to expose the vocabulary standards among the experimental and control groups. The consolidated score sheets of control and experimental groups were analyzed and tabulated under the competence levels of average, above average, good and excellent. 


\section{Analysis:}

The below table reveal the marks scored by the control and experimental groups in the pre-test. A brief summary of the findings is also depicted in this section.

\begin{tabular}{|l|l|l|l|l|l|}
\hline \multirow{2}{*}{ Scores } & \multirow{2}{*}{\begin{tabular}{l} 
Competency \\
\cline { 3 - 6 }
\end{tabular}} & & \multicolumn{2}{|l|}{ Control Group } & \multicolumn{2}{l|}{ Experimental group } \\
\cline { 3 - 6 } & & No & $\%$ & No & $\%$ \\
\hline 45 and above & Excellent & Nil & --- & Nil & --- \\
\hline $31-45$ & Good & 2 & $7 \%$ & 5 & $17 \%$ \\
\hline $16-30$ & Average & 26 & $86 \%$ & 25 & $83 \%$ \\
\hline 15 and less & Poor & 2 & $7 \%$ & 0 & - \\
\hline Total & & 30 & $100 \%$ & 30 & $100 \%$ \\
\hline
\end{tabular}

Table: 2

\section{Findings:}

- Excellent--- Control Group- Nil and Experimental Group- Nil

- Good --- Control Group- 7\% and Experimental Group- 17\%

- Average --- Control Group- 86\% and Experimental Group- 83\%

- Poor --- Control Group- 7\% and Experimental Group- 17\%

The results of the pre-test have stressed the necessity of strategy training among the engineering students. Hence, the strategy training was given to the experimental group against this background.

\section{Strategy Training}

The pre-test conducted among the control and experimental groups reveals that only a few of the engineering students are sound in vocabulary knowledge. The assessment result of their performance is discussed among them in groups basing on the similar percentage of marks. Later, the researcher decided to conduct training to the experimental group in their leisure periods such as sports and meditation classes with the due permission of the college authorities. The experimental group of students showed willingness and participated throughout the training sessions enthusiastically. Thus, the strategy training was given to the experimental group (Mechanical Engineering) of LakiReddy BaliReddy College of Engineering and Technology situated at Mylavaram in Andhra Pradesh. Altogether seven activities were done for training seven elements of vocabulary. Therefore, the total training sessions were conducted to the experimental group for 4 periods of 50 minutes each.

\section{Materials Used for Vocabulary Strategy Training:}

The materials used for the training are flash cards, teaching aids, dictionaries, worksheets and handout downloaded from internet and self-prepared are used to instruct training among the experimental group. 


\section{Context based Strategies in Learning Sentence Completion:}

The students of experimental group are allowed to guess vocabulary from the given context and discover the meaning of new words. They are taught to:

- Identify the context in which the word is used.

- $\quad$ Scrutinize what is before and after the word.

- Assemble their thoughts and knowledge of the word.

- $\quad$ Predict a possible meaning.

- $\quad$ Finally resolve or re-do the whole process.

The experimental group of students is trained to decide if they know enough, should try again or consult an expert or refer dictionary. Therefore, Guessing strategies may be applied to complete the sentences.

\section{Procedure}

Gradually, they suggested relevant words and then finally actual words that are suitable to be filled in the gaps provided in the passages.

\section{Activity: Guessing Words}

Once -------Susan decided to try out the ------ chairs which were placed around the ------ table. She sat on the tiny chair. She said, 'I like this ---------- chair.' But it ------- to tiny Baby bear and it ----- down when Susan sat on it! The little girl ------ and went up to see if she could find a ---- bed to sleep on.

\section{Observation:}

- $\quad$ Out of 30 students of experimental group, only a few of them are able to interpret the context in which the words are used.

- Most of them are passive.

- $\quad$ The researcher prompted them frequently to bring out response from them.

Thus, motivation is essential to enable students learn a new language.

\section{Concept Based Strategies in Learning Synonyms and Antonyms}

Concept based strategies are helpful in finding new relationship in old language and relating this new information to old knowledge. Students are taught to learn new words, related concepts and their meanings and opposites.

\section{Procedure:}

The experimental group is instructed to activate their prior knowledge of a few words. Later, key vocabulary words are introduced that are similar in meaning to the target words. Thus, the researcher has:

- Written a word on the blackboard that represents the key concept.

- Asked them think of words that relate to the key word and other words that do not relate to the key word. 
- $\quad$ Advised them to group all the words in different categories

- $\quad$ Finally, presented new words before in discussions.

\section{Activity: Semantic Mapping}

As a part of Strategies Inventory training, the researcher has applied Semantic Mapping Strategy in enhancing synonyms and antonyms. Semantic maps organize prior knowledge of the students into formal relations and provide a basis for understanding.

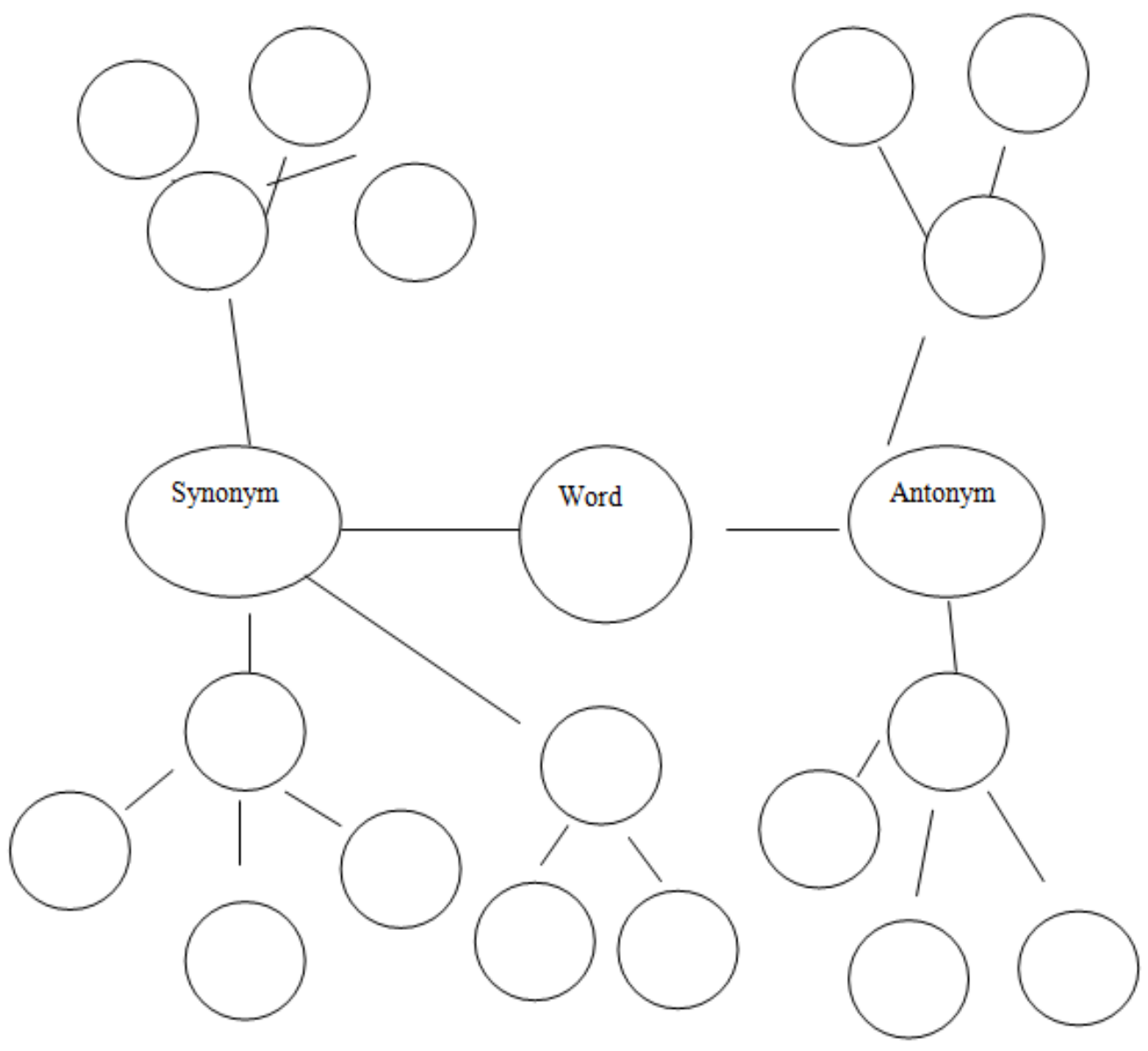




\section{Observation:}

- The students were enthusiastic in learning new words.

- They were interested to do the activity in groups

- Gradually through semantic strategy they appeared confident.

\section{Word Association Strategies in Learning Analogies:}

Analogy is one of the verbal ability sections that have to be attempted and fare well in the entrance and placement tests by the engineering students. Analogies determine the relationship between a pair of stem and find the same relationship in one of the pairs from the options.

\section{Procedure:}

The experimental group is instructed to identify the relationship between the stem words. An example is provided to them... What is the relationship between morning and breakfast? It enabled the students to guess the relationship. They replied that breakfast is consumed in the morning. Thus, morning is the daytime and breakfast is the food consumed. In this way the students were encouraged to identify the relationship between several pairs of words.

\section{Exercises}

1. Skyscraper: Shack::

i. Elevator: Escalator ii. Village: Town iii. Jetliner: Biplane

The students are given a few minutes to solve the Analogy and identify the relationship between the stem words-Skyscraper-Shack. The students took several minutes to recognize the relation and finally revealed that skyscraper is large and shack is small. Later, they concluded that skyscraper is large and modern and small version of it is Shack. The researcher next instructed them to find the similar pair among the options by provoking them with the following questions:

- Is elevator a large and modern version of escalator? A few of them answered yes while others replied no.

- Is house a large and modern version of building? They all disagreed.

- Is village a large and modern version of town? Definitely not is the reply received from the students.

- Is a jetliner large and modern version of a bi-plane? They thought for a while and responded that 'of course, yes.'

- Finally, the researcher was able to bring about good responses from the students through prompting and guidance. 


\section{Activity: Word Association Map}
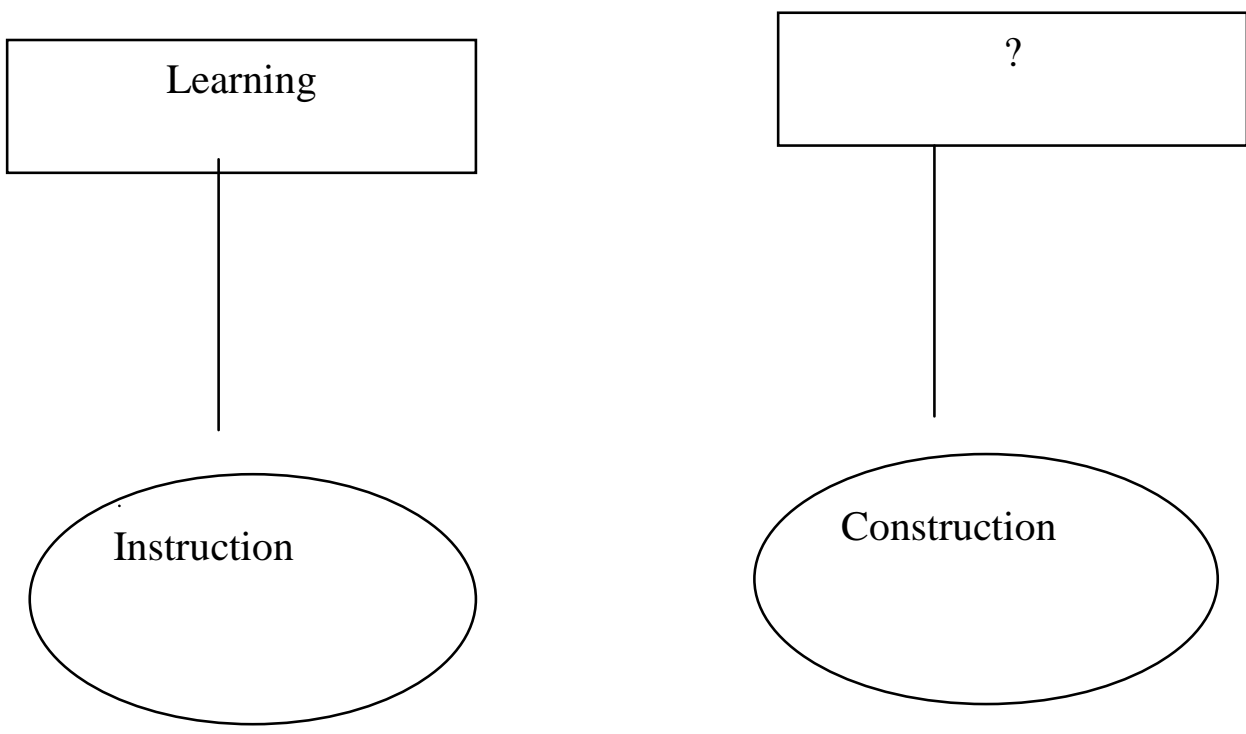

Instruction is to learning as Construction is to-----------

\section{Identifying the Errors:}

An attempt is made by the researcher to identify the errors in a sentence and rectify them.

\section{Materials:}

A few sentences from GRE, SAT, GMAT entrance tests are taken to impart training in spotting the errors in the sentences.

\section{Procedure:}

- $\quad$ Firstly, the students are given the following sentence:

- Ex: Everyone is excited about the party next weekend and I am definitely one of the people who are going.

- They are asked whether anything is wrong with the given sentence. The response is amazing. They replied that there is something wrong with the sentence.

- They were instructed to strike off the correct choices and underline the mistakes in the sentence.

- $\quad$ The following words are underlined by the students-

- $\quad$ Everyone is_excited about the party next weekend and I am definitely one of the people who are going.

- $\quad$ The students were advised to apply their knowledge of grammar to identify errors.

- Gradually, with the help of the researcher they concluded that are does not fit with everyone. While others thought that end of the sentences may be wrong... people who are.

- $\quad$ Finally, the students are able to identify the errors and rectified.

Wrong: Everyone are excited about the party next weekend and I am definitely one of the people who are going.

Correct: Everyone is excited about the party next weekend and I am definitely one of the people that are going. 


\section{Learning One Word Substitute:}

Often, the engineering students need to apply their vocabulary knowledge in supplying one word for the sentences and phrases.

\section{Materials:}

Flash cards are used to impart instructions in supplying words for a few sentences and phrases.

\section{Procedure:}

- The students were divided into two teams. One of the teams was given the cards on which a sentence or phrase was written and the other team was given cards with one word substitutes for those sentences and phrases.

- $\quad$ They were instructed to select one representative. The role of the representative is to stand and display the card on which a sentence is written.

- $\quad$ The second team members were advised to identify the one word substitute for the sentence revealed by the first team representative among the flash cards received by them in the beginning.

- $\quad$ The second team started guessing the correct option. Some of them discussed, while others suggested and advised among themselves.

- $\quad$ Finally, they were able to pick out the appropriate flash card displaying one word substitute for the sentence.

\section{Activity:}
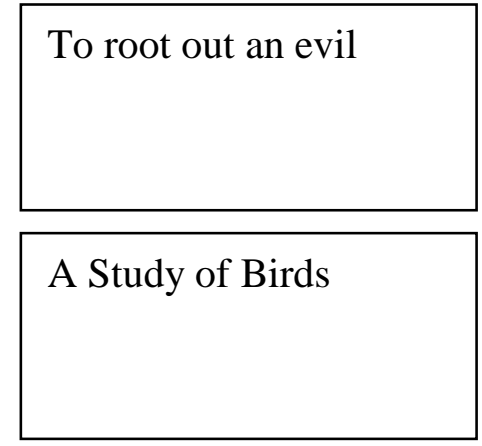

Moving heavily and clumsily

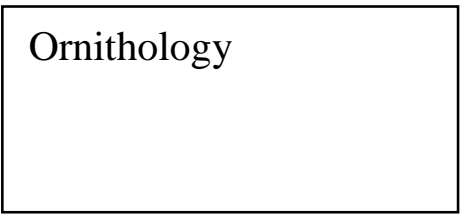

Eradicate

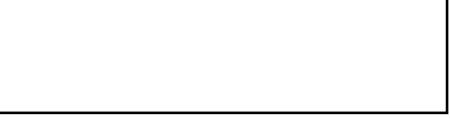

$$
\text { Tepid }
$$

\section{Observation:}

The students were comfortable in working out in teams. They were at liberty to discuss and suggest alternatives in front of their peers. The outcome of this activity is splendid and students were contended with their own performances. 


\section{Post-Research:}

Thus, the strategy training was carried out by the researcher for about 4 theory periods. Later, a post-test was conducted among both the control and experimental groups to find out the effectiveness of the strategy training. The following topics are selected as the basis for the post-test. (Annexure: 2)

\section{Post-Test}

\begin{tabular}{|l|l|l|}
\hline Topic & Marks & Duration \\
\hline Synonyms & $5 \mathrm{M}$ & $5 \mathrm{mts}$ \\
\hline Antonyms & $5 \mathrm{M}$ & $5 \mathrm{mts}$ \\
\hline Analogy & $10 \mathrm{M}$ & $10 \mathrm{mts}$ \\
\hline One word substitutes & $10 \mathrm{M}$ & $10 \mathrm{mts}$ \\
\hline Common Errors & $10 \mathrm{M}$ & $10 \mathrm{mts}$ \\
\hline Sentence completion & $10 \mathrm{M}$ & $10 \mathrm{mts}$ \\
\hline Total & $50 \mathrm{M}$ & $50 \mathrm{mts}$ \\
\hline
\end{tabular}

Table: 3

The vocabulary elements are selected by the researcher keeping in mind the strategy training provided among the experimental group.

\section{Analysis of Marks scored by Two Groups in Post-Test:}

The below table reveal the marks scored by the control and experimental groups in the pre-test. A brief summary of the findings is also depicted in this section.

\begin{tabular}{|l|l|l|l|l|l|}
\hline \multirow{2}{*}{ Scores } & Competency Level & \multicolumn{2}{|l|}{ Control Group } & \multicolumn{2}{l|}{ Experimental group } \\
\cline { 3 - 6 } & & No & $\%$ & No & $\%$ \\
\hline 45 and above & Excellent & Nil & - & 17 & $57 \%$ \\
\hline $31-45$ & Good & 1 & $3 \%$ & 10 & $33 \%$ \\
\hline $16-30$ & Average & 20 & $67 \%$ & 3 & $10 \%$ \\
\hline 15 and less & Poor & 9 & $30 \%$ & & \\
\hline Total & & 30 & & 30 & \\
\hline
\end{tabular}

Table: 4 


\section{Findings:}

- $\quad$ Excellent--- Control Group- Nil

- Good --- Control Group- 3\%

- $\quad$ Average --- Control Group- 67\%

- $\quad$ Poor --- Control Group- 30\%
Experimental Group- 57\%

Experimental Group- 33\%

Experimental Group- $10 \%$

Experimental Group- Nil

After a short period of strategy training sessions conducted to the experimental group, a post-test was administered among both the control and experimental groups to make comparisons and also to understand whether the strategy training was useful to the students. The results of the post-test have stressed the significance of strategy training among the engineering students.

Further, the analysis of marks scored by the control and experimental groups are provided separately in the tabular form.

\section{Analysis of Marks- Control Group in Pre-Test and Post-Test:}

The post-test was conducted to 30 students of the control group belonging to Mechanical branch. The number and percentage of students falling under the various levels of competence in English are provided in the below table.

Number and Percentage of Control Group in Pre-Test and Post-Test:

\begin{tabular}{|c|c|c|c|c|c|}
\hline \multirow[t]{2}{*}{ Scores } & \multirow[t]{2}{*}{ Competency Level } & \multicolumn{2}{|c|}{ Pre-Test } & \multicolumn{2}{|c|}{ Post-Test } \\
\hline & & No & $\%$ & No & $\%$ \\
\hline $\begin{array}{l}45 \text { and } \\
\text { above }\end{array}$ & Excellent & Nil & - & Nil & - \\
\hline $31-45$ & Good & 2 & $7 \%$ & 1 & $3 \%$ \\
\hline $16-30$ & Average & 26 & $86 \%$ & 20 & $67 \%$ \\
\hline $\begin{array}{l}15 \text { and } \\
\text { less }\end{array}$ & Poor & 2 & $7 \%$ & 9 & $30 \%$ \\
\hline Total & & 30 & & 30 & \\
\hline
\end{tabular}

Table: 5

The marks clearly indicate that there is hardly any difference in the percentage of Good and Average users of the English language from the two tests even after a period of one month of course work in the classroom. Surprisingly the percentage of Average users is reduced while that of Poor users is increased.

Further, a comparative analysis was made by studying the averages of marks scored by the group in different sections of the two tests. The averages of the Pre-Test and Post-Test are presented in the below table. 
Marks of Control Group in Four Sections- Pre-Test and Post-Test

\begin{tabular}{|l|l|l|l|l|l|l|l|l|l|l|l|}
\hline \multirow{2}{*}{ Scores } & \multicolumn{9}{|l|}{ Pre-Test } & \multicolumn{2}{|l|}{ Post-Test } \\
\cline { 2 - 13 } & I & II & III & IV & V & I & II & III & IV & V & VI \\
\hline $\begin{array}{l}45 \text { and } \\
\text { above }\end{array}$ & -------- & ------- & ------- & ------- & ------- & ------- & ------- & ------- & ------- & ------- & ------- \\
\hline $31-45$ & 3.0 & 8.5 & 5.0 & 2.0 & 9.0 & 2.0 & 3.0 & 10.0 & 10.0 & 6.0 & 6.0 \\
\hline $16-30$ & 3.3 & 6.8 & 3.5 & 4.6 & 5.7 & 1.4 & 2.6 & 2.8 & 4.0 & 2.2 & 2.8 \\
\hline $\begin{array}{l}15 \text { and } \\
\text { less }\end{array}$ & 2.5 & 6.5 & 2.0 & 1.0 & 2.0 & 1.7 & 2.2 & 2.8 & 4.6 & 3.9 & 14.6 \\
\hline Total & 8.8 & 21.8 & 10.5 & 7.6 & 16.7 & 5.1 & 7.8 & 15.6 & 18.6 & 12.1 & 13.4 \\
\hline Average & 2.9 & 7.1 & 3.5 & 2.5 & 5.5 & 1.7 & 2.6 & 5.2 & 6.2 & 4.0 & 4.4 \\
\hline
\end{tabular}

Table: 6

Therefore, the data given in the table reveal that the section wise scores of the two tests by the control group do not show any noticeable improvement and thereby the skills of the group have remained almost the same. Since, they have already taken similar test, the control group showed a slight improvement in a few sections.

\section{Findings \& Inferences:}

It can be inferred that the competence levels remained the same among the students of the control group that was not given any overt strategy training. The slight improvement that is perceived is bound to be there in any group that receives a class work input which is skill based with the method of learning that is communicative. The course work for the B.Tech students under the JNTUK and ANU affiliated colleges is designed with an overt emphasis on CLT methods and techniques both for English (Theory) and English Communication Skills (Practical).

\section{Analysis of Marks- Experimental Group in Pre-Test and Post-Test}

The number and percentage of students under the various levels of competence in the two tests are given in the below table. 


\section{Number \& Percentage of Experimental Group in Pre-Test and Post-Test}

\begin{tabular}{|l|l|l|l|l|l|}
\hline \multirow{2}{*}{ Scores } & Competency Level & \multicolumn{2}{|l|}{ Pre-Test } & \multicolumn{2}{l|}{ Post-Test } \\
\cline { 3 - 6 } & & No & $\%$ & No & $\%$ \\
\hline $\begin{array}{l}45 \text { and } \\
\text { above }\end{array}$ & Excellent & Nil & --- & 17 & $57 \%$ \\
\hline $31-45$ & Good & & & & $33 \%$ \\
\hline $16-30$ & Average & 5 & $17 \%$ & 10 & $10 \%$ \\
\hline 15 and less & Poor & 25 & $83 \%$ & 3 & \\
\hline Total & & 0 & - & & \\
\hline
\end{tabular}

Table: 7

Analysis of the data from the above table indicates that:

- There is a perceptible increase in the proportion of the excellent users in their performance in the pre-test compared to that of post-test. The percentage of excellent user category increased from zero to $57 \%$.

- $\quad$ The percentage of good user category rose from $17 \%$ to $33 \%$.

- The average users are considerably more in the pre-test than in the post-test. This may be due to improvement in their performance and may have fallen either in the excellent users' list or good users' list. Hence, the percentage of average users decreased from $83 \%$ to $10 \%$.

- Another observation is that the strategy training has shown a considerable impact on the students.

\section{Averages of Four Sections in Pre-Test \& Post-Test by Experimental Group}

The averages in all the sections were calculated. The table shows the averages of each section in the competence level category. The class average was calculated by scrutinizing the averages of each category vertically in the table.

\section{Averages of Sections in Pre-Test \& Post-Post by Experimental Group}

\begin{tabular}{|c|c|c|c|c|c|c|c|c|c|c|c|}
\hline \multirow[t]{2}{*}{ Scores } & \multicolumn{5}{|c|}{ Pre-Test } & \multicolumn{6}{|c|}{ Post-Test } \\
\hline & I & IV & III & II & $\mathrm{V}$ & I & II & III & IV & $\mathrm{V}$ & VI \\
\hline $\begin{array}{l}45 \text { and } \\
\text { above }\end{array}$ & ------- & ------ & ------ & ------ & ----- & 4.7 & 4.5 & 10.0 & 9.5 & 9.7 & 9.7 \\
\hline $31-45$ & 5.0 & 6.0 & 8.8 & 5.0 & 7.2 & 4.8 & 4.6 & 9.6 & 8.2 & 9.2 & 8.6 \\
\hline
\end{tabular}




\begin{tabular}{|l|l|l|l|l|l|l|l|l|l|l|l|}
\hline $16-30$ & 2.2 & 2.7 & 5.6 & 7.2 & 4.1 & 3.0 & 4.6 & 7.3 & 4.0 & 3.3 & 5.3 \\
\hline $\begin{array}{l}15 \text { and } \\
\text { less }\end{array}$ & ------ & ----- & ----- & ----- & ----- & ------ & ------ & ----- & ------ & ------- & ------ \\
\hline Total & 7.2 & 8.7 & 14.4 & 12.2 & 11.3 & 12.5 & 13.8 & 26.9 & 15.7 & 22.2 & 23.6 \\
\hline Average & 3.6 & 4.3 & 7.2 & 6.1 & 5.6 & 4.1 & 4.6 & 8.9 & 15.2 & 7.4 & 7.8 \\
\hline
\end{tabular}

Table: 8

The data reveals that the class average in all the sections shows an increase after strategy training. They performed better in other sections of the post -test compared to that of pre-test.

\section{Findings and Inferences}

The above data reveals that the performance of students belonging to the experimental group does show a positive feedback for the utility of strategy training. It can be presumed that the language skills of the engineering students would surely improve if strategy training is provided.

\section{Analysis of Marks Scored by Control and Experimental Groups in Post-Test}

60 students of both control and experimental group wrote the post-test. An analysis of data of both the groups in the two tests and a comparison with their own performance in pre-test was studied earlier.

The below table is an attempt to study compare the marks of the two groups.

\begin{tabular}{|c|c|c|c|c|c|}
\hline \multirow[t]{2}{*}{ Scores } & \multirow[t]{2}{*}{ Competency Level } & \multicolumn{2}{|l|}{ Control Group } & \multicolumn{2}{|c|}{ Experimental Group } \\
\hline & & Number of students & $\%$ & $\begin{array}{l}\text { Number of } \\
\text { students }\end{array}$ & $\%$ \\
\hline $\begin{array}{l}45 \text { and } \\
\text { above }\end{array}$ & Excellent & Nil & - & 17 & $57 \%$ \\
\hline $31-45$ & Good & 1 & $3 \%$ & 10 & $33 \%$ \\
\hline $16-30$ & Average & 20 & $67 \%$ & 3 & $10 \%$ \\
\hline $\begin{array}{l}15 \text { and } \\
\text { less }\end{array}$ & Poor & 9 & $30 \%$ & Nil & - \\
\hline Total & & 30 & & 30 & \\
\hline
\end{tabular}

Table: 9 
The data from the table shows that

- There are no students whose competence level is excellent among the control group. While the percentage of students whose competence level is excellent among the experimental group has increased.

- The number of good users is only 1 whereas the experimental group is 10 . Hence, there is an increase in the percentage of control group--- 3\% than that of experimental group is $33 \%$.

- The percentage of average users among experimental group is only $10 \%$ while that of control group is $67 \%$.

- The percentage of poor users is nil in the experimental group, whereas it is $30 \%$ in control group.

It proves that the majority of the experimental group has fallen under the excellent and good users due to the strategy training.

Analysis of the data reveals that the experimental group shows a better competence level in English than the control group the when their skills are tested.The analysis that was made before the strategy training to draw the profile of the control and experimental groups revealed that there was no difference between them concerning English proficiency. Nevertheless, analysis taken after the strategy training depicts a diverse picture. Similarly the comparative study of the competence levels between the two groups in the pre and post test shows a marked difference. These aspects are signs to confirm that the strategy training course is beneficial. Further, an attempt is made to compare the averages of the different sections among both the groups in their performance in Post-Test.

\section{Averages: Four Sections of Post-Test - Control \& Experimental Groups}

\begin{tabular}{|c|c|c|c|c|c|c|c|c|c|c|c|c|}
\hline \multirow[t]{2}{*}{ Scores } & \multicolumn{6}{|c|}{ Control Group } & \multicolumn{6}{|c|}{ Experimental Group } \\
\hline & $\mathrm{I}$ & II & III & IV & $\mathrm{V}$ & VI & $\mathrm{I}$ & II & III & IV & $\mathrm{V}$ & VI \\
\hline $\begin{array}{l}45 \text { and } \\
\text { above }\end{array}$ & --- & --- & --- & --- & --- & --- & 4.7 & 4.5 & 10.0 & 9.5 & 9.7 & 9.7 \\
\hline $31-45$ & 2.0 & 3.0 & 10.0 & 10.0 & 6.0 & 6.0 & 4.8 & 4.6 & 9.6 & 8.2 & 9.2 & 8.6 \\
\hline $16-30$ & 1.4 & 2.6 & 2.8 & 4.0 & 2.2 & 2.8 & 3.0 & 4.6 & 7.3 & 4.0 & 3.3 & 5.3 \\
\hline $\begin{array}{l}15 \text { and } \\
\text { less }\end{array}$ & 1.7 & 2.2 & 2.8 & 4.6 & 3.9 & 14.6 & ------ & ----- & $\mid----$ & ------ & ------ & ----- \\
\hline Total & 5.1 & 7.8 & 15.6 & 18.6 & 12.1 & 13.4 & 12.5 & 13.8 & 26.9 & 15.7 & 22.2 & 23.6 \\
\hline Average & 1.7 & 2.6 & 5.2 & 6.2 & 4.0 & 4.4 & 4.1 & 4.6 & 8.9 & 15.2 & 7.4 & 7.8 \\
\hline
\end{tabular}

Table: 10 
Thus, the analysis of data reveals that the experimental group shows a better competence level in English than the control group in all the sections of the post-test.

When an analysis was made to draw the profile of the control and experimental groups the data revealed that there were no predominant differences between the two groups. However the analysis after the strategy training projects a different representation. There is a wide gap between the competence levels in all sections. The section wise difference between the control and experimental group is as following:

- $\quad$ I section --------- 1.7 and 4.1

- $\quad$ II section --------- 2.6 and 4.6

- $\quad$ III section --------- 5.2 and 8.9

- $\quad$ IV section --------- 6.2 and 15.2

- $\quad$ V section --------- 4.0 and 7.4

- $\quad$ VI section ---------- 4.4 and 7.8

These factors are indicators to prove that the strategy training course has been beneficial.

\section{Observations:}

The researcher noticed the following striking observations during the strategy training provided to the experimental.

1. The students were initially withdrawn but slowly got rid of their inhibitions and participated freely.

2. They chose likeminded peers for group work and pair work.

3. They were willing to help each other during the entire training period.

4. They became open to peer group correction which was a positive inter dependence in Cooperative Learning.

5. They showed interest in the activities and participated actively.

6. The guessing strategies were proven to be beneficial in improving their skills.

7. They tried to perform some of the activities autonomously.

Thus, the similar performance among the control and experimental groups before strategy training and the difference in the post strategy training period is a clear indication that the training has been helpful.

The present study highlights the fact that language learning can be most favourable and effective when learners are aware of their own strategies. Moreover, the focus in the recent years has been on learners and how learning takes place. It is an attempt to prove that the product of learning and the process of learning make students self-reliant. The strategy training has motivated them to take the responsibility of employing strategies in learning the target language.

The present study has surveyed the Engineering colleges of Andhra Pradesh to find out the necessity of strategy training. It tries to find out the LLS often applied by the students of Engineering colleges situated at three major districts ----Krishna, Guntur and Prakasam in Andhra Pradesh. 
Annexure: 1

\section{Pre-Test}

\section{Target Group: Engineering Students}

\section{Time: 50 minutes}

Marks: 50

Dear Student,

This test is prepared to find out the vocabulary proficiency among students of Engineering \& Technology affiliated to JNTUK and ANU. The researcher assures you that the marks would be kept confidential and used only for the purpose of data collection and survey in research. Kindly mark tick in the brackets provided indicating the correct option.

Afsha Jamal

\section{Select the word that conveys the same meaning to the following words from the} alternatives given below

$10 \times 1=10 M$

1. Amenable
a. Agreeable
b. Responsive
c. Insulting
d. Justified

2. Lethal
a. Deadly
b. Sluggish
c. Smooth
d. Unlawful

3. Vocation
a. Holidays
b. Employee
c. Occupation
d. Hobby

4. Flex
a. Remove
b. Bend
c. Fold
d. Move

5. Accede
a. Compromise
b. Correct
c. Consent d. Mollify

6. Chaste
a. Loyal
b. Timid
c. Pure
d. Outspoken

7. Eminent
a. Distinguished
b. Purposeful
c. detectable
d. Urgent

8. Enigmatic
a. Complicated
b. Illusive
c. Puzzling
d. Pitiful

9. Solace
a. Happiness
b. Holiday
c. Consolation
d. Rest

10. Waive
a. Restrict
b. Relax
c. Permit
d. Admit

\section{Out of the four alternatives, choose the one that can be substituted for the given phrases $10 \times 1=10 \mathrm{M}$}

11. A speech delivered without preparation

a. Verbose b. Extempore c. Maiden d. Straightforward

12. People working in the same department or office

a. Colleagues b. Fellows c. Mates d. Companies

13. A physician who specializes in diseases of skin 

a. Obstetrician b. Cardiologist c. Dermatologist d. Geriatrician

14. Account of a person's life written by another

a. Autobiography b. Biography c. Philosophy d. Monologue

15. Person who does not believe in the existence of God

a. Atheist b. Theist c. Ascetic d. Bigot

16. Something that becomes outdated

a. Old b. ancient c. obsolete d. Useless

17. One who sacrifices his life for a cause

a. Martyr b. Patriot c. Soldier d. Revolutionary

18. One who looks at right side of things
a. Pessimist b. Optimist c. Hedonist
d. Hypocrite

19. A tank in which fish are kept
a. Aquacade b. Aquatint c. Aqua tone
d. Aquarium

20. A person who studies the formation of the earth
a. Geologist
b. Anthropologist c. Meteorologist d. Seismologist

III. Choose the one that best expresses the meaning of the italicized idioms/phrases.

21. To strain every nerve
a. To spoil relationship
b. To get afraid
c. To try one's utmost
d. To take ill

22. A hard nut to crack
a. One who is very obstinate
b. Very difficult child
c. A walnut or a fruit
d. Problem that is hard to be solved

$10 \times 1=10 M$

23. Once in a blue moon
a. Frequently
b. Rarely
c. Always
d. Never

24. Keep the Ball Rolling
a. Continue the work
b. Spin the ball
c. Stop the work
d. Kick the ball

25. A feather in one's cap
a. Prize
b. Achievement
c. Appreciation
d. A Cap with feathers

26. See eye to eye
a. Fight
b. Angry
c. Agree
d. Disagree

27. Chip of the old block

a. Similar to his father 
b. A good actor

c. An honourable man

d. Outdated in his manners

28. Be in High spirits
a. Drunken state
b. Cheerful mood
c. Talking incoherently
d. Deeply engrossed in thoughts

29. To have an axe to grind
a. Pinpoint fault of others
b. To take revenge
c. Make reasonable demands
d. Selfish interest to serve

30. Mind one's P's and Q's
a. Be careful with language
b. B. Be accurate and precise
c. Learn alphabets
d. Never forget P's and Q's

\section{Identify the suitable changed voice of the following sentences from the alternatives given below $5 \times 2=10$}

31. After driving professor Kumar to the museum she dropped him at his hotel. ( )

a. After being driven to the museum, Professor Kumar was dropped at his hotel.

b. Professor Kumar was being driven dropped at his hotel.

c. After she had driven Professor Kumar to the museum she had dropped him at his hotel.

d. After she was driven Professor Kumar to the museum she had dropped him at his hotel.

32. Who is creating this mess?
a. Who has created this mess?
b. By whom has this mess been created?
c. By whom this mess is being created?
d. By whom is this mess being created?

33. Darjleeng grows tea
a. Tea is being grown in Darjleeng
b. Let the tea be grown in Darjleeng
c. Tea is grown in Darjleeng
d. Tea grows in Darjleeng

34. I was greeted cheerfully
a. They greet him cheerfully
b. They greeted him cheerfully
c. He greeted them cheerfully
d. They are greeting him cheerfully

35. He will be coming tomorrow
a. He is coming tomorrow
b. He may come tomorrow
c. He will come tomorrow
d. He comes tomorrow 
V. Choose the suitable changed speech of the following sentences from the alternatives given below $5 \times 2=10 \mathrm{M}$

36. He said to her, "Why don't you go today?"
a. He asked her why she did not go that day
b. He said to her why she doesn't go that day
c. He asked her not to go that day
d. He asked her why she did not go that day

37. Smitha ordered her servant $o$ bring her a cup of tea
a. Smitha told her servant, "Bring a cup of tea"
b. Smitha said, "Bring me a cup of tea"
c. Smitha said to her servant, Bring me a cup of tea"
d. Smitha told her servant, "Bring her that cup of tea"

38. Hari said that he was sick and tired of working for that company"
a. Hari said, I am sick and tired of working for this company"
b. Hari said, "He was tired of that company"
c. Hari said to me, "I am sick and tired of working for this company"
d. Hari said, "I will be tired of working for that company"

39. "Are you alone, my son?" asked a soft voice close behind me
a. A soft voice asked that what I was doing there alone
b. A soft voice said to me are you alone son
c. A soft voice from my back asked if I was alone
d. A soft voice behind me asked if I was alone

40. She said, "I am not feeling well?
a. She that I was not feeling well
b. She said that she was not feeling well
c. She said that she is not well
d. She said that she was well not 


\section{Annexure: 2}

\section{Post-Test}

\section{Target Group: Engineering Students}

\section{Time: 50 minutes}

Marks: 30

Dear Student,

This test is prepared to find out the improvement among the experimental group after the strategy training classes. The researcher assures you that the marks would be kept confidential and used only for the purpose of data collection and survey in research. Kindly mark tick in the brackets provided indicating the correct option.

Afsha Jamal

I. Select the word that is similar in meaning to the key words from the alternatives given below

1. Culpable
a. Correct
b. Guilty
c. Right
d. Innocent

\section{$5 \times 1=5 M$}

2. Intrinsic
a.Damaging
b. Deteriorating
c. Enlarging
d. Inherent

3. Oblivious
a. Nervous
b. Unaware
c. Familiar
d. Irritated

4. Averse
a. Vow
b. Discourage
c. Reluctant
d. Liberal

5. Countenance
a. Fear
b. Confidence
c. Adorn
d. Tolerate

II. Select the word that is opposite in meaning to the key words from the alternatives given below
6. Transmit
a Show
b. Reply
c. Withhold
d. Televise

7. Thrive
a. Survive
b. Revive
c. Entertain
d. Deteriorate

8. Radiate
a.Approach
b. Cool
c. Absorb
d. Tarnish

9. Benign
a. Sick b. Poor
c. Damaged
d. Evil

10. Analysis
a.Dialysis
b. Electrolysis
c. Parenthesis
d. Synthesis

\section{$5 \times 1=5 M$}

( )

( )

)

)

( )

III. Each of the questions below consists of two words that have a certain relationship to each other. Select the pair of words having a relationship similar to the first pair. $5 \times 1=5 M$

11. Partnership: Corporation
a. Two: Man b. Local: National c. Unlimited: Limited
d. Agreement: Conspiracy

12. Brush:Paint 
a. Trowel: Cement b. Hammer: Nail c. Match: Fire d. Polish: Floor

13.Solution:Mystery

a. Education: Books b. Learning: Study c. Library: Silence

d. Spy: Detective

14.Large:Small
a. Giant: Heavy
b. Huge: Dwarf c. Thin: Lean
d. Big: Slim

15.Promise:Fulfill

a. Pawn: Redeem b. Law: Enforce

c. Pledge: Deny d. Prisoner: Release

IV. Out of the four alternatives, choose the one word that can be substituted for the given phrases $5 \times 1=5 M$

16. A place that provides refuge

a. Asylum b. Sanatorium c. Shelter d. Orphanage

17. One who feels at home in every country
a. Metropolitan
b. Cosmopolitan
c. Citizen
d. Denizen

18. Speaking extremely well
a. Elocution
b. Stammering
c. Orator
d. Extempore

19. Study of Birds
a. Anthropology
b. Ornithology
c. pathology
d. Biology

20. Disease lasting for a long time
a. Epidemic
b. Plague
c. Chronic
d. Endemic

V. Each of the following sentences are divided into parts, which are marked A,B,C, and D. One of these parts contains an error or may not be acceptable in standard written communication. Identify that part

$5 \times 1=5 M$

21. A wise (A)/ and experienced manager will assign (B)/ a job to whomever (C)/ is best qualified

22. When (A)/her plane arrives(B)/ at the airport in Amritsar, I shall already have(C) left to New Delhi(D) 
23. Every (A)/ man, woman and child are now (B)/ aware of the (C)terrible consequences of the bad habit of smoking(D)

24. No sooner (A)/ had he entered (B)/ the hall when the (C)/ lights went out and everybody began to scream (D)

25. One of (A)/ my student (B)/ tells me (C)/ that she has failed in English(D) ( )

\section{Complete the following sentences with an appropriate word from the below given alternatives $5 \times 1=5 \mathrm{M}$}

26. Gandhiji was a humble man known for his ----
a. Sweetness
b. pleasantness
c. modesty
d. kindness

27. Professionals focus their ---- on fulfilling their responsibilities
a. Planning
b. Skills
c. Leadership
d. Energies

28. Man is still a ---- in the labour market
a. Commodity
b. Provision
c. Glut
d. Possibility

29. The ---- manner of the officer dispelled all his fears
a. Haughty
b. Amiable
c. Genial d. Fickle

30. The teacher must ---- the unique style of the learner in order to harness it to the desired knowledge
a. Advocate
b. Appreciate
c. Absorb
d. Discover 